\section{Contabilidade Geral e o Desempenho dos Estudantes no Exame de Suficiência: uma pesquisa com IES baianas.}

\author{
Thiago Rios Sena \\ UFBA - Universidade Federal da Bahia \\ thiagoriossena@gmail.com \\ Jonatas Dutra Sallaberry \\ UFSC - Universidade Federal de Santa Catarina \\ jonatas.sallaberry@hotmail.com
}

\title{
Resumo
}

O Exame de Suficiência é responsável por avaliar os conhecimentos médios dos bacharéis em Ciências Contábeis, possibilitando o mercado receber profissionais com competências e habilidades mínimas para 0 desempenho da função, bem como é requisito para o registro no conselho profissional. Esta pesquisa tem como objetivo analisar a relação entre a carga horária das disciplinas de Contabilidade Geral nas Instituições de Ensino Superior (IES) na Bahia e o desempenho dos respectivos estudantes no Exame de Suficiência do Conselho Federal de Contabilidade (CFC). $O$ trabalho foi desenvolvido a partir de análise documental e descritiva com as 37 IES de uma edição anual, a partir de dados do CFC e da análise da matriz curricular de cada IES. Para análise dos dados foram utilizadas técnicas de correlação e regressão linear. Os resultados encontrados revelam que não é possível afirmar que há relação entre a carga horária empregada pelas IES para os conteúdos de Contabilidade Geral e análogas com o desempenho dos alunos dessas IES no Exame de Suficiência. Entretanto, por meio das variáveis de controle percebe-se que o desempenho possui relação com fatores inerentes ao próprio discente, como o correspondente desempenho no ENADE, e principalmente a natureza institucional da IES.

Palavras-chave: Exame de Suficiência. Currículo. Desempenho.

ISSN: 1984-6266

Recebimento:

$18 / 12 / 2020$

Aprovação:

08/03/2021

Editor responsável pela aprovação do artigo:

Dra. Luciana Klein

Editor responsável pela edição do artigo:

Dra. Luciana Klein

Avaliado pelo sistema:

Double Blind Review

A reprodução dos artigos, total ou parcial, pode ser feita desde que citada a fonte.

PROGRAMA DE PÓS-GRADUAÇ̃̃O EM CONTABILIDADE

UFre MESTRADO E DOUTORADO

DOl:

http://dx.doi.org/10.5380/rcc.v13i1.78581 


\title{
BASIC ACCOUNTING AND STUDENT PERFORMANCE IN THE SUFFICIENCY EXAM: A SURVEY WITH HEIS OF BAHIA
}

\begin{abstract}
The Sufficiency Exam is responsible for assessing the average knowledge of bachelor's in accounting, enabling the market to receive professionals with minimum competencies and skills to perform the function, as well as being a requirement for registration with the professional council. This research aims to analyze the relationship between the workload of the Basic Accounting disciplines in Higher Education Institutions (HEls) in Bahia and the performance of the respective students in the Sufficiency Exam of the Federal Accounting Council (FAC). The work was developed from documentary and descriptive analysis with a $37 \mathrm{HEls}$ of an annual edition, from data from the CFC and from the analysis of the curriculum matrix of each HEI. For data analysis, correlation and linear regression techniques were used. The results found reveal that it is not possible to affirm that there is a relation between the workload employed by the HEls for the contents of Basic Accounting and similar ones with the performance of these HEls in the Sufficiency Exam. However, through the control variables, it is noticed that the students' performance is related to factors inherent to the student himself, such as the corresponding performance in ENADE, and especially the institutional nature of the HEl.
\end{abstract}

Keywords: Sufficiency Exam. Curriculum. Performance.

\section{Introdução}

O Exame de Suficiência foi inicialmente instituído por meio de resolução pelo Conselho Federal de Contabilidade (CFC) em 1999 - Resolução CFC n 853 (CFC, 1999), sendo aplicado até 2005, e posteriormente em 2010 a partir da Lei no 12.249 (Brasil, 2010).

O Exame de Suficiência é requisito para obtenção do registro profissional como Contador, e diante disso as instituições de ensino enfrentaram um cenário de adequação para garantir que o seu aluno alcance 0 critério de suficiência. Essa adequação se torna necessária uma vez que a universidade tem como objetivo a preparação do graduando para atuação no mercado de trabalho, e essa está diretamente ligada à obtenção do título de Contador por meio do Exame de Suficiência.

Outros trabalhos científicos buscaram examinar o desempenho dos estudantes de Ciências Contábeis em provas como o Exame Nacional de Desempenho de Estudantes (ENADE) e o Exame de Suficiência, entretanto nenhum deles apresentou a Contabilidade Geral como variável relevante (Moraes, 2005; Quintana, Perazo, \& Fernandes, 2013; Castilho, 2013; Fraga \& Broietti, 2016).

Tendo em vista a relevância desse tipo de comparação, a falta de correlações fortes e buscando um resultado ainda não apresentado, traz-se como tema desse trabalho a identificação da relação entre a carga horária das disciplinas de Contabilidade Geral nas diferentes Instituições de Ensino Superior (IES) na Bahia e o desempenho dos respectivos estudantes no Exame de Suficiência do Conselho Federal de Contabilidade.

Ao analisar o ensino da contabilidade, as atenções devem estar centradas na verificação de como as Instituições de Ensino Superior (IES) estão provendo, quantitativa e qualitativamente, os seus estudantes para que estejam realmente preparados ou em condições mínimas para o exercício da profissão que escolheram.

Dentre os conteúdos abordados por esse exame, a Contabilidade Geral é o que apresenta o maior número de itens descritos nos editais dos últimos Exames de Suficiência, além do maior número de questões nas últimas edições. Outrossim, Contabilidade Geral é a base teórica para o desenvolvimento de qualquer outro 
assunto tratado pela Contabilidade, o que demonstra a relevância desse conteúdo na formação do graduando e aprovação no Exame de Suficiência.

Por meio desse artigo pretende-se responder a seguinte problemática: Existe relação entre a carga horária referente nas disciplinas de Contabilidade Geral e o desempenho dos estudantes no Exame de Suficiência no estado da Bahia? Assim, este estudo teve como objetivo verificar a existência da relação entre carga horária da grade curricular do curso de ciências contábeis de diferentes IES baianas e o rendimento dos estudantes no Exame de Suficiência, com foco nas disciplinas relacionadas à Contabilidade Geral.

Diante disso, faz-se necessário um estudo acerca da estrutura da grade curricular das IES em comparação com os conteúdos abordados no Exame de Suficiência, assim como os índices de aprovação a fim de verificar a existência de relação entre eles. Ao verificar a correlação entre o índice de aprovação no Exame de Suficiência e o total de carga horária de Contabilidade Geral nas IES, esta pesquisa contribui à literatura contábil, no que tange ao processo de ensino superior em contabilidade. Ademais, este trabalho contribui, sob o aspecto social, ao proporcionar informação auxiliar à tomada de decisão de coordenadores dos cursos de Ciências Contábeis, por exemplo na reestruturação de grades curriculares.

\section{Fundamentação Teórica}

\subsection{Exame de Suficiência}

A formação Contábil teve sua relevância destacada na Lei no 12.249/2010 que alterou as normas que regulamentam a profissão no Brasil (Decreto-Lei n 9.295/1946). Após essa publicação, a responsabilidade pela fiscalização do exercício da profissão Contábil ficou a cargo do Conselho Federal de Contabilidade (CFC) e dos Conselhos Regionais de Contabilidade (CRCs). De acordo com a alteração da legislação, os profissionais contábeis somente poderão exercer a profissão após regular conclusão do Curso Bacharelado em Ciências Contábeis, reconhecido pelo Ministério da Educação, aprovação em Exame de Suficiência e o registro no Conselho Regional de Contabilidade a que estiverem sujeitos.

O Exame de Suficiência já tinha sido aplicado entre os anos de 2000 a 2005, sendo instituído por meio de resolução do próprio CFC e outros atos normativos. Em seguida fora considerado como inconstitucional pelo Supremo Tribunal Federal (STF), uma vez que feriu o Princípio Constitucional do Livre Exercício da Profissão.

A partir da instituição da Lei no 12.249/2010, o CFC retomou a exigência da aprovação no Exame de Suficiência para alcance do registro profissional de Contador. De acordo com a Resolução CFC n. 1.486 (2015), o "Exame de Suficiência é a prova de equalização destinada a comprovar a obtenção de conhecimentos médios, consoante os conteúdos programáticos desenvolvidos no curso de Bacharelado em Ciências Contábeis".

O Exame de Suficiência é uma ferramenta utilizada para garantir a qualidade de formação dos Contadores. De acordo com Kounrouzan (2010), a implantação do Exame de Suficiência trouxe melhorias do ensino superior, fazendo com que os novos profissionais tenham um maior conhecimento geral, com uma visão global do mundo, sendo capazes de tomar decisões mais rápidas e inteligentes. 0 retorno do Exame de Suficiência como requisito para o exercício profissional como Contador é imprescindível para essa classe, afinal a prova visa garantir um padrão mínimo na qualidade técnica dos serviços contábeis.

Cruz (2011) afirma que a qualificação da classe contábil está se intensificando e que os empresários que buscam um profissional diferenciado estão considerando isso como um fator importante. Sendo assim o Exame de Suficiência possibilita avaliar os novos profissionais como melhor qualificados para exercerem a profissão, podendo impactar em remunerações mais adequadas ao nível de conhecimento obtido. 
A prova de suficiência é realizada em todo o país semestralmente, sendo composta por 50 questões conforme assuntos descritos em edital específico para cada edição. Para obter a aprovação no exame, é necessário que o candidato alcance no mínimo $50 \%$ de acertos, ou seja, 25 questões corretas.

\subsection{Contabilidade Geral e o Exame de Suficiência}

O Conselho Federal de Contabilidade (CFC) lista treze (13) áreas de conhecimento que compõe as questões do Exame de Suficiência, para os Bacharéis em Ciências Contábeis: Contabilidade Geral, Contabilidade de Custos, Contabilidade Aplicada ao Setor Público, Contabilidade Gerencial, Controladoria, Noções de Direito e Legislação Aplicada, Matemática Financeira e Estatística, Teoria da Contabilidade, Legislação e Ética Profissional, Princípios de Contabilidade e Normas Brasileiras de Contabilidade, Auditoria Contábil, Perícia Contábil e Língua Portuguesa Aplicada (CFC, 2020).

O número de questões de Contabilidade Geral se destaca nos Exames tornando esse conteúdo como estratégico para obtenção do título de Contador. A importância dessa área de conhecimento pode ser expressa a partir da sua relevante presença nesse exame, conforme revela Rabelo (2017) ao indicar que mais da metade das questões tratam de elementos básicos da contabilidade, como Contabilidade Geral, Princípios, Normas e Pronunciamentos Contábeis - CPCs.

A Contabilidade Geral versa sobre os conceitos, princípios gerais, fundamentos e práticas que se aplicam a qualquer campo da contabilidade. Conforme De Negri (2012), a Contabilidade Geral, ou outras nomenclaturas atribuídas pelos diversos currículos, aborda o patrimônio, as operações contábeis, as regras contábeis, a escrituração, os inventários, os balanços, os orçamentos e a contabilidade como gestão.

Marion (2001) ao tratar do ensino da disciplina de Contabilidade Geral, destaca a sua importância para o desenvolvimento do estudante durante o curso de graduação, indicando que ela é a base para as demais temáticas de contabilidade aplicada. Segundo o mesmo autor, essa disciplina seria fundamental, cuja perfeita aprendizagem e sedimentação dependeria para um bom aproveitamento do curso - a espinha dorsal do curso de Ciências Contábeis.

As disciplinas englobadas pela Contabilidade Geral contemplam assuntos introdutórios, abordando conceitos iniciais relevantes na formação do futuro profissional e necessários para atingir os objetivos abaixo descritos. Seu conteúdo está relacionado com parte das exigências estabelecidas pelas Diretrizes Curriculares para o Curso de Graduação em Ciências Contábeis, instituídas pela Resolução CNE/CES n. 10 (Brasil, 2004), do Conselho Nacional de Educação.

Os assuntos abordados referentes ao conteúdo de Contabilidade Geral, conforme o Edital do Exame de Suficiência, edição n 1/2020, podem ser sintetizados nos tópicos: Patrimônio e Variações Patrimoniais, Plano de Contas e Procedimentos de Escrituração, Avaliação de Ativos e Passivos, Mensuração e Reconhecimento de Operações, Operações Fiscais, Tributárias e de Contribuições, Combinação de Negócios, Balanço Patrimonial, Demonstração do Resultado e Demonstração do Resultado Abrangente, Demonstração dos Lucros ou Prejuízos Acumulados, Demonstração das Mutações do Patrimônio Líquido, Demonstração dos Fluxos de Caixa, Demonstração do Valor Adicionado, Notas explicativas, Consolidação das Demonstrações Contábeis, Efeitos das mudanças nas taxas de câmbio e conversão das Demonstrações Contábeis e Sistema Público de Escrituração Digital.

\subsection{Ensino da Contabilidade e o Exame de Suficiência}

O ensino de contabilidade nas IES e a sua relação com o Exame de Suficiência foi abordada por Madeira, Mendonça e Abreu (2003) que destacam este como um indicador de qualidade para as respectivas 
instituições. Além de permitir a habilitação profissional, o Exame de Suficiência pode servir de apoio às IES no processo de avaliação e acompanhamento dos currículos, pois mediante os exames é possível verificar os conteúdos exigidos e compará-los com aqueles ministrados, permitindo identificar deficiências, 0 aprimoramento dos cursos e, consequentemente, reduzindo as reprovações (Madeira, Mendonça, \& Abreu, 2003).

As universidades e faculdades que ofertam o curso de Ciências Contábeis podem utilizar o Exame de Suficiência como um balizador de sua estrutura curricular, adaptando-se as mudanças para levar 0 conhecimento atualizado aos profissionais contabilistas. As IES têm a incumbência de planejar os conteúdos e a grade curricular dos seus cursos para que aborde a técnica necessária ao exercício da profissão, além de promover o desenvolvimento das competências e habilidades para a atuação da prática contábil (CNE, 2004).

A área contábil é dinâmica, sendo influenciada constantemente por alterações em leis e procedimentos, logo o contador precisa estar sempre se reciclando e inovando para atender as exigências do mercado (Marion, 2001). Assim entende-se que o Exame de Suficiência seja o primeiro degrau para a qualificação profissional, sendo a graduação um importante instrumento para o cumprimento dessa etapa.

Diversos outros trabalhos buscaram analisar a estrutura de grades curriculares do curso de Ciências Contábeis em IES no Brasil, cada um sob uma metodologia e enfoque diferente, fazendo comparações e buscando uma forma de evidenciar relação entre a estrutura das disciplinas e o Exame de Suficiência ou ENADE (Castilho, 2013; Fraga \& Broietti, 2016; Quintana, Perazo, \& Fernandes, 2013; Moraes, 2005). Entre as pesquisas nessa direção, destaca-se algumas que apresentam tema voltado para o assunto em questão.

Moraes (2005) desenvolveu pesquisa que objetivou investigar e analisar o nível de relacionamento entre grades curriculares e o desempenho dos alunos do curso de Bacharelado em Ciências Contábeis, das IES da Paraíba que se submeteram ao Exame de Suficiência. Os resultados revelaram que, analisando a grade por completo e sem destacar uma área específica de conhecimento, tanto a carga horária quanto a quantidade de disciplinas ofertada e a natureza das instituições não explicam o desempenho do Exame de Suficiência.

Já o estudo realizado por Quintana, Perazo e Fernandes (2013) foi mais específico, tendo como objetivo analisar a carga horária das disciplinas da área de contabilidade financeira e orçamentária nas IES, que ofertam o curso de Ciências Contábeis, com a intenção de investigar se existe uma relação com resultado do ENADE, nas instituições que obtiveram conceito entre 3 e 5 . Em sua conclusão, a análise mostrou uma correlação fraca entre a carga horária das disciplinas e o conceito obtido pelas IES estudadas.

Fraga e Broietti (2016) apresentaram um artigo que teve como objetivo verificar a relação entre a grade curricular de um curso de Ciências Contábeis em uma Universidade localizada no norte do Paraná em comparação com os conteúdos aplicados nos Exame de Suficiência e no ENADE. De maneira geral, foi identificado que todas as questões do Exame de Suficiência e do ENADE analisadas na pesquisa tinham relação com alguma disciplina ofertada no curso estudado, entretanto existiam diferenças de proporcionalidade entre a carga horária de algumas disciplinas e o número de questões, seja em menor ou maior razão.

A Contabilidade de Custos também foi objeto de pesquisa ao ter o conhecimento dos estudantes comparados aos respectivos desempenhos no Exame de Suficiência. Castilho (2013) verificou que o alto índice de aprovação no exame de suficiência não se justifica necessariamente pelo conhecimento em Contabilidade de Custos, mas de outras matérias que compõem no Exame de Suficiência.

Diante do que foi apresentado até então, tem-se como hipótese que carga horária de disciplinas relativas ao conteúdo de Contabilidade Geral é um fator que contribui para o índice de aprovação das IES.

Alguns estudos na literatura acadêmica já discutiram sobre o valor agregado das Instituições de Ensino, como Coleman (1966) e Jencks (1972) concluíram que aspectos familiares e características do ambiente social tem maior impacto na performance dos estudantes que as características individuais das instituições de ensino. Thomas (1998) e Thomas e Mortimore (1996) observaram que cerca de 70 a $75 \%$ da variação de performance 
dos estudantes da Educação Secundária no Reino Unido é proveniente das medidas de admissão dos alunos, sendo os outros $20-25 \%$ o valor agregado pelas instituições de ensino e outros fatores externos.

O resultado da pesquisa de Ferreira (2015) levanta a hipótese que as Instituições Públicas tenham maiores índices em exames de desempenho não apenas pelas condições institucionais, mas, muito mais pelo perfil de alunos que ingressam na IES pública. Na conclusão de seu estudo, as características e atitudes dos alunos são as maiores responsáveis para determinação do desempenho acadêmico, enquanto apenas 10\% ficam a cargo das variáveis institucionais.

Soares, Martins e Assunção (1998) explicam que as IESs que admitem os alunos mais bem preparados ao fim do ensino médio, que são, frequentemente, também aqueles de melhor condição social e econômica, apresentarão desempenho superior nos Exames de desempenho ao final da graduação. Soares, Ribeiro e Castro (2001) encontram resultados que, para o curso de Direito em universidades e faculdades de Minas Gerais, as IESs são responsáveis apenas por uma pequena parcela do desempenho, representando cerca de $6 \%$ na diferença de rendimento do estudante (valor agregado).

Bertolin e Marcon (2015) afirmam que o fator que mais impacta o desempenho dos graduandos em exames como o ENADE é o capital cultural, formado pelo contexto familiar, social, econômico e cultural dos estudantes, portanto as diferenças entre os cursos das IES pouco influenciam nos resultados obtidos pelos estudantes em exames.

Para mensurar os conceitos mencionados acima, foram utilizadas, respectivamente, as variáveis proxy: Conceito da Instituição (Cl), Conceito Preliminar de Curso (CPC), nota no Exame Nacional de Desempenho de Estudantes (ENADE) e a carga horária total dos cursos de ciências contábeis já analisados nesse trabalho.

O Conceito Institucional é uma avaliação in loco feita pelos especialistas do Ministério da Educação (MEC), atribuindo uma nota entre 1 a 5. São realizadas visitas às instalações da instituição, analisando-as como um todo, principalmente seu Plano de Desenvolvimento Institucional (PDI), sua gestão, políticas de pessoal, políticas para a o ensino de graduação, pós-graduação, pesquisa e extensão. Esse indicador será utilizado como proxy de atributo de cada Instituição de Ensino, afinal o $\mathrm{Cl}$ pode ser considerado como uma referência para atestar a qualidade da IES (Casartelli, 2015).

O Conceito Preliminar de Curso (CPC) é um indicador de qualidade que avalia os cursos de graduação. Seu cálculo é baseado na avaliação de desempenho dos estudantes, no valor agregado pelo processo formativo e em insumos referentes às condições de oferta - corpo docente, infraestrutura e recursos didáticopedagógicos (INEP, 2018a).

O ENADE tem como objetivo avaliar o desempenho dos estudantes com relação aos conteúdos programáticos previstos nas diretrizes curriculares dos cursos de graduação, o desenvolvimento de competências e habilidades necessárias ao aprofundamento da formação geral e profissional, e o nível de atualização dos estudantes com relação à realidade brasileira e mundial (INEP, 2018b). O conceito é apresentado em cinco categorias (1 a 5), sendo que 1 é o resultado mais baixo e 5 é o melhor resultado possível, na área. Baseado na hipótese de Ferreira (2015) citada no item anterior, esse conceito será utilizado nesse estudo como proxy para medir o desempenho inerente ao estudante.

\section{Procedimentos Metodológicos}

Para o levantamento de dados, no campo da pesquisa descritiva, que objetiva conhecer e interpretar a realidade sem nela interferir para modificá-la, foi realizada uma pesquisa documental e análise de dados. Para Helder (2006), utilizando a técnica documental o autor vale-se de documentos originais, que ainda não receberam tratamento analítico por nenhum outro, sendo uma das técnicas decisivas para a pesquisa em ciências sociais e humanas. 
Assim, após a coleta de dados, empregou-se técnicas estatísticas como a correlação e regressão linear para analisar evidências, desenvolver questionamentos e argumentos lógicos, além de propor inferências sobre 0 assunto. A amostra foi selecionada por conveniência da região norte e nordeste do Brasil, devido à importância de se contribuir com o desenvolvimento regional. Devido ao potencial quantitativo de IES, optouse pelo Estado de maior quantitativo de inscritos, e um dos melhores desempenhos nessas regiões - 0 Estado da Bahia.

Nesse estudo, foram analisadas as grades curriculares das IES atuantes no estado da Bahia, que foram selecionadas a partir da listagem dos relatórios estatísticos no site do CFC. A amostra foi selecionada pelo total de IES que apresentaram resultados nas duas edições do Exame de Suficiência em 2017.

Foi identificada a listagem (Recuperado de http://cfc.org.br/registro/exame-de-suficiencia/relatoriosestatisticos-do-exame-de-suficiencia/) com 105 unidades de IES no estado da Bahia. Entretanto, o site do CFC passou a divulgar os relatórios estatísticos apresentando o índice de aprovação por IES apenas a partir da primeira edição de 2017, fazendo com que os dados ficassem restritos a esse período. Ainda foram identificadas 9 IES que tiveram menos que 10 estudantes presentes nas edições mencionadas, que por opção dos pesquisadores foram excluídas da análise para evitar viés com uma amostra relativamente pequena em comparação às outras instituições. Dessa forma, 47 IES ainda se encontravam elegíveis para análise da Grade Curricular.

Para essa análise foram utilizadas as Grades Curriculares que as IES disponibilizam em seus respectivos websites. Cada matéria foi classificada, baseada em sua ementa, como um dos 13 assuntos contidos no Edital do Exame de Suficiência edição n. ${ }^{0}$ 2/2017. Portanto, o caráter subjetivo de avaliação do autor pode refletir em pequenas variações quanto a mensuração da carga horária das disciplinas. Dentre a IES listadas, 10 IES não disponibilizam a matriz curricular online, não sendo possível avaliá-las. Dessa forma, a análise completa restringe-se a $37(66 \%)$ das 56 IES descritas no relatório estatístico do CFC, destacados na Tabela 1.

Tabela 1 - Quantidade de IES presentes no estudo.

\begin{tabular}{|c|c|c|}
\hline Amostragem & Qtd. & Percentual \\
\hline Número Total de IES listadas no relatório estatístico do CFC: & 56 & $100 \%$ \\
\hline Número de IES com menos de 10 presentes nos Exames: & 9 & $16 \%$ \\
\hline Número de IES que não disponibilizam a Grade Curricular online: & 10 & $18 \%$ \\
\hline Número de IES analisadas no artigo: & 37 & $66 \%$ \\
\hline
\end{tabular}

Fonte: Dados da Pesquisa (2020).

Em virtude da pequena população e exclusão de IES que não possuíam a Matriz Curricular disponível online, ou baixo número de presentes para realização do Exame de Suficiência, a amostragem não pôde ser realizada de forma probabilística, o que reduziria ainda mais a amostra e poderia comprometer de forma mais acentuada a pesquisa.

Adicionalmente, para complementar e controlar a amostra, foram inseridos conceitos qualitativos das IES, sendo os indicadores de Conceito Institucional (Cl), Conceito Preliminar de Curso (CPC) e Exame Nacional de Desempenho de Estudantes (ENADE). 
Todos os dados referentes a esses três últimos indicadores de cada IES foram obtidos no Cadastro eMEC de Instituições e Cursos de Educação Superior (Recuperado de http://emec.mec.gov.br/). Para tratamento dos missings, foi utilizada a técnica de imputação do valor médio para cada variável, a fim de evitar causar um impacto mais danoso à pesquisa reduzindo o tamanho da amostra (Assunção, 2012).

Antes de efetuar a análise principal que se propõe esse artigo, foi necessário explorar outros dados, como: a incidência histórica das questões do Exame de Suficiência para comprovar a superioridade em número daquelas referente à Contabilidade Geral; a relação das IES estudadas nessa pesquisa, assim como sua natureza e índice de aprovação; e a distribuição relativa dos assuntos do Exame de Suficiência na grade curricular de cada IES.

A análise estatística, inicialmente, foi desenvolvida utilizando a Correlação Linear para verificar a existência de relação entre o percentual de aprovação dos alunos de cada IES no Exame de Suficiência e a carga horária das disciplinas relacionadas à Contabilidade Geral. Após esse resultado, utilizou-se a Regressão Linear Múltipla para verificar a possível influência de outros fatores no índice de aprovação de cada instituição no Exame de Suficiência.

\section{Análise dos Resultados}

Nessa seção serão apresentados os dados gerados a partir dos relatórios estatísticos disponíveis no site do CFC e da classificação das disciplinas de cada IES selecionada, elaborando comparações a fim de evidenciar os tópicos abordados nos objetivos específicos e outras constatações.

\subsection{Conteúdo do Exame de Suficiência}

Baseado nas informações divulgadas pelo CFC e sua classificação quanto ao conteúdo das cinco provas anteriores disponíveis no site, a Tabela 2 demonstra o número de questões de cada assunto por edição do Exame de Suficiência, seu número total e a relação percentual.

Tabela 2 - Número de questões por Exame de Suficiência

\begin{tabular}{c|c|c|c|c|c|c|c|c}
\hline Conteúdo & Legenda & $\mathbf{1 / 2 0 1 7}$ & $\mathbf{2 / 2 0 1 6}$ & $\mathbf{1 / 2 0 1 6}$ & $\mathbf{2 / 2 0 1 5}$ & $\mathbf{1 / 2 0 1 5}$ & Total & \% Total \\
\hline Auditoria Contábil & AC & 2 & 3 & 3 & 3 & 3 & 14 & $5,6 \%$ \\
\hline $\begin{array}{c}\text { Contabilidade Aplicada ao } \\
\text { Setor Público }\end{array}$ & CASP & 3 & 3 & 3 & 3 & 3 & 15 & $6,0 \%$ \\
\hline $\begin{array}{c}\text { Contabilidade de Custos } \\
\text { Contabilidade Geral }\end{array}$ & CG & 3 & 3 & 3 & 4 & 4 & 17 & $6,8 \%$ \\
\hline $\begin{array}{c}\text { Contabilidade Gerencial } \\
\text { CGeren }\end{array}$ & 21 & 22 & 21 & 17 & 15 & 96 & $38,4 \%$ \\
\hline $\begin{array}{c}\text { Controladoria } \\
\text { Profissional }\end{array}$ & C & 1 & 2 & 0 & 0 & 0 & 3 & $1,2 \%$ \\
\hline $\begin{array}{c}\text { Legislac̃ão e Ética } \\
\text { Crop }\end{array}$ & 2 & 1 & 2 & 3 & 3 & 11 & $4,4 \%$ \\
\hline
\end{tabular}


Contabilidade geral e o desempenho dos estudantes no exame de suficiência: uma pesquisa com IES baianas.

\begin{tabular}{c|c|c|c|c|c|c|c|c}
\hline Língua Portuguesa Aplicada & LPA & 2 & 1 & 2 & 3 & 3 & 11 & $4,4 \%$ \\
\hline $\begin{array}{c}\text { Matemática Financeira e } \\
\text { Estatística }\end{array}$ & MFE & 2 & 2 & 2 & 3 & 3 & 12 & $4,8 \%$ \\
\hline $\begin{array}{c}\text { Noções de Direito e } \\
\text { Legislação Aplicada }\end{array}$ & NDL & 3 & 3 & 3 & 3 & 3 & 15 & $6,0 \%$ \\
\hline Perícia Contábil & PC & 2 & 3 & 3 & 2 & 2 & 12 & $4,8 \%$ \\
\hline $\begin{array}{c}\text { Princípios de Contabilidade e } \\
\text { Normas Brasileiras de } \\
\text { Contabilidade }\end{array}$ & PCNBC & 3 & 3 & 3 & 3 & 4 & 16 & $6,4 \%$ \\
\hline $\begin{array}{c}\text { Teoria da Contabilidade } \\
\text { Total }\end{array}$ & TC & 4 & 2 & 2 & 2 & 3 & 13 & $5,2 \%$ \\
\hline
\end{tabular}

Fonte: CFC (2020)

Pode-se perceber que Contabilidade Geral é o assunto que possui maior número de questões por prova, tendo como média uma ocorrência relativa de $38,4 \%$. Sabendo que o percentual mínimo para aprovação do candidato é de $50 \%$, fica evidente a importância do domínio desse conteúdo para obtenção do título de Contador.

Oposto a isso, as questões acerca de Controladoria apresentam-se apenas em 1,2\% das questões analisadas. Essa disciplina foi inserida no conteúdo da prova somente a partir da segunda edição de 2016, devido a mudança do perfil do Contador pelos avanços tecnológicos. Foi apresentado duas questões nesse exame e uma na prova seguinte. Os demais 11 conteúdos apresentaram número relativo de questões bem próximos, tendo seus percentuais entre 4,4 e $6,8 \%$.

\subsection{Instituições de Ensino Superior da Bahia}

Após identificação das IES e seus respectivos índices de aprovação no exame de suficiência demonstrados na Tabela 3, foram tabulados os dados divulgados pelo CFC referente à duas edições de 2017 e únicas disponíveis que revelam o índice de aprovação por IES. Por opção dos autores, o ranking na Tabela 3 está sendo evidenciado somente até a décima colocação.

Tabela 3 - Amostra das IES analisadas

\begin{tabular}{c|l|c|c|c}
\hline Ranking & \multicolumn{1}{|c|}{ Instituição de Ensino Superior } & Sigla & Natureza & Aprovação \\
\hline 1 & Universidade Estadual do Sudoeste da Bahia & UESB & Pública & $74,29 \%$ \\
\hline 2 & Universidade Federal da Bahia & UFBA & Pública & $55,22 \%$ \\
\hline 3 & Universidade Estadual de Santa Cruz & UESC & Pública & $53,33 \%$ \\
\hline 4 & Universidade Estadual de Feira de Santana & UEFS & Pública & $41,67 \%$ \\
\hline
\end{tabular}


Thiago Rios Sena \& Jonatas Dutra Sallaberry.

\begin{tabular}{c|l|c|c|c}
\hline 5 & Faculdade Ruy Barbosa & FRB & Privada & $39,36 \%$ \\
\hline 6 & Faculdade de Ciências Humanas e Sociais & AGES & Privada & $35,71 \%$ \\
\hline 7 & Faculdade do Sul da Bahia & FASB - T & Privada & $34,62 \%$ \\
\hline 8 & Centro Universitário Jorge Amado & UNIJORGE & Privada & $33,33 \%$ \\
\hline 9 & Centro Universitário Estácio da Bahia & FIB & Privada & $33,33 \%$ \\
\hline 10 & Faculdade Independente do Nordeste & FAINOR & Privada & $33,10 \%$ \\
\hline Fonte: Dados da Pesquisa (2020) & & & \\
\hline
\end{tabular}

Fonte: Dados da Pesquisa (2020)

Ao analisar o índice de aprovação de cada IES identifica-se uma diferença de 66,6\% entre o maior e menor resultado da amostra, de 74,29\% referente à UESB à 7,69\% do menor desempenho analisado. Percebese uma queda significativa de rendimento entre as três primeiras colocadas no ranking apresentado $(74,29 \%$, $55,22 \%$ e 41,67\%), logo em seguida essa diminuição de aprovação é mais sutil.

É possível afirmar que a UESB tem um índice de aprovação acima das demais IES. Faz-se necessária uma análise acerca dessa discrepância positiva para que seja possível replicar nas demais e qualificar melhor os estudantes da Bahia.

Além disso, é possível verificar que dentre as 37 IES avaliadas, apenas 5 são de natureza pública, sendo que 4 delas estão entre as 4 melhores IES avaliadas. A UNEB é a única IES pública que teve IES particulares com melhores avaliações, assumindo a $11^{a}$ posição no contexto geral.

\subsection{Carga horária total das disciplinas nas IES}

A partir das matrizes e grades curriculares disponibilizadas no site de cada IES, foi possível obter todas as disciplinas que fazem parte da sua respectiva graduação em ciências contábeis. Consultando a ementa de cada disciplina e baseado no julgamento dos pesquisadores, foi relacionada cada uma delas à um conteúdo descrito no último edital do Exame de Suficiência (segunda edição de 2017).

A Tabela 4 apresenta a quantidade relativa da carga horária de cada conteúdo por IES, acompanhada do percentual de aprovação (desempenho) de cada IES e da carga horária de contabilidade geral.

Tabela 4 - Quantidade relativa de horas por disciplina e IES

\begin{tabular}{|c|c|c|c|c|c|c|c|c|c|c|c|c|c|c|c|c|}
\hline 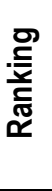 & 웡 & 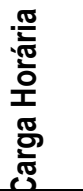 & $\frac{\circ}{\frac{0}{\pi}}$ & ن̀ & $\begin{array}{l}\stackrel{0}{0} \\
\text { के } \\
\frac{1}{0}\end{array}$ & 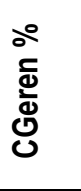 & ن̊ & $\begin{array}{l}\text { ㅇ } \\
\text { Dे }\end{array}$ & 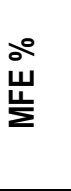 & ن̊ & $\begin{array}{l}\text { ㅇ } \\
\text { 㞻 }\end{array}$ & $\begin{array}{l}\text { نீ } \\
\text { 罗 }\end{array}$ & O̊ & ல̊ & ¿̊ & 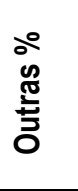 \\
\hline 1 & 74,3 & 420 & 14,6 & 4,2 & 4,2 & 10,4 & 2,1 & 10,4 & 8,3 & 2,1 & 2,1 & 0,0 & 4,2 & 2,1 & 2,1 & 33,3 \\
\hline 2 & 55,2 & 340 & 12,2 & 2,4 & 4,9 & 7,3 & 2,4 & 9,8 & 9,8 & 2,4 & 2,4 & 0,0 & 7,3 & 2,4 & 2,4 & 34,1 \\
\hline 3 & 53,3 & 480 & 16,7 & 2,1 & 4,2 & 8,3 & 0,0 & 8,3 & 10,4 & 2,1 & 2,1 & 0,0 & 4,2 & 2,1 & 2,1 & 37,5 \\
\hline 4 & 41,7 & 450 & 17,4 & 2,2 & 4,3 & 10,9 & 0,0 & 8,7 & 8,7 & 2,2 & 2,2 & 0,0 & 2,2 & 2,2 & 2,2 & 37,0 \\
\hline
\end{tabular}


Contabilidade geral e o desempenho dos estudantes no exame de suficiência: uma pesquisa com IES baianas.

\begin{tabular}{|c|c|c|c|c|c|c|c|c|c|c|c|c|c|c|c|c|}
\hline 5 & 39,3 & 480 & 20,0 & 2,5 & 5,0 & 12,5 & 2,5 & 5,0 & 7,5 & 2,5 & 2,5 & 0,0 & 2,5 & 2,5 & 2,5 & 32,5 \\
\hline 6 & 35,7 & 320 & 10,3 & 2,6 & 5,1 & 10,3 & 0,0 & 10,3 & 7,7 & 0,0 & 2,6 & 0,0 & 2,6 & 2,6 & 2,6 & 43,6 \\
\hline 7 & 34,6 & 540 & 20,5 & 4,5 & 2,3 & 6,8 & 2,3 & 9,1 & 9,1 & 2,3 & 2,3 & 0,0 & 2,3 & 2,3 & 2,3 & 34,1 \\
\hline 8 & 33,3 & 638 & 17,6 & 2,0 & 2,0 & 5,9 & 3,9 & 7,8 & 5,9 & 2,0 & 2,0 & 0,0 & 2,0 & 3,9 & 2,0 & 43,1 \\
\hline 9 & 33,3 & 560 & 18,8 & 2,1 & 4,2 & 6,3 & 2,1 & 4,2 & 10,4 & 2,1 & 0,0 & 0,0 & 4,2 & 2,1 & 4,2 & 39,6 \\
\hline 10 & 33,1 & 570 & 20,0 & 4,0 & 4,0 & 6,0 & 2,0 & 10,0 & 8,0 & 2,0 & 2,0 & 0,0 & 2,0 & 2,0 & 2,0 & 36,0 \\
\hline 11 & 26,2 & 420 & 13,2 & 3,8 & 5,7 & 1,9 & 1,9 & 9,4 & 9,4 & 1,9 & 1,9 & 0,0 & 3,8 & 1,9 & 1,9 & 43,4 \\
\hline 12 & 25,7 & 390 & 12,3 & 1,8 & 1,8 & 5,3 & 1,8 & 7,0 & 8,8 & 1,8 & 1,8 & 0,0 & 3,5 & 1,8 & 1,8 & 50,9 \\
\hline 13 & 25,6 & 360 & 11,9 & 4,8 & 2,4 & 7,1 & 2,4 & 9,5 & 9,5 & 2,4 & 2,4 & 0,0 & 4,8 & 2,4 & 4,8 & 35,7 \\
\hline 14 & 24,4 & 600 & 17,8 & 4,4 & 4,4 & 4,4 & 2,2 & 8,9 & 6,7 & 2,2 & 2,2 & 0,0 & 2,2 & 2,2 & 2,2 & 40,0 \\
\hline 15 & 24,1 & 480 & 14,3 & 3,6 & 3,6 & 3,6 & 1,8 & 7,1 & 5,4 & 1,8 & 1,8 & 0,0 & 5,4 & 1,8 & 1,8 & 48,2 \\
\hline 16 & 23,1 & 540 & 17,4 & 2,2 & 4,3 & 6,5 & 2,2 & 6,5 & 4,3 & 2,2 & 0,0 & 0,0 & 4,3 & 0,0 & 2,2 & 47,8 \\
\hline 17 & 23,0 & 576 & 17,4 & 2,2 & 4,3 & 10,9 & 2,2 & 6,5 & 6,5 & 2,2 & 0,0 & 0,0 & 2,2 & 2,2 & 2,2 & 41,3 \\
\hline 18 & 22,7 & 420 & 14,0 & 4,0 & 2,0 & 4,0 & 2,0 & 6,0 & 8,0 & 2,0 & 2,0 & 0,0 & 4,0 & 2,0 & 2,0 & 48,0 \\
\hline 19 & 21,9 & 432 & 14,6 & 4,9 & 2,4 & 4,9 & 2,4 & 9,8 & 9,8 & 2,4 & 2,4 & 0,0 & 2,4 & 2,4 & 2,4 & 39,0 \\
\hline 20 & 21,4 & 360 & 13,0 & 2,2 & 4,3 & 6,5 & 2,2 & 10,9 & 6,5 & 2,2 & 2,2 & 0,0 & 2,2 & 2,2 & 2,2 & 43,5 \\
\hline 21 & 20,7 & 460 & 16,7 & 4,2 & 2,1 & 2,1 & 2,1 & 8,3 & 12,5 & 0,0 & 2,1 & 0,0 & 2,1 & 2,1 & 2,1 & 43,8 \\
\hline 22 & 19,6 & 520 & 20,5 & 4,5 & 4,5 & 6,8 & 4,5 & 6,8 & 9,1 & 2,3 & 4,5 & 0,0 & 4,5 & 2,3 & 2,3 & 27,3 \\
\hline 23 & 18,5 & 640 & 16,7 & 2,1 & 2,1 & 10,4 & 2,1 & 6,3 & 6,3 & 2,1 & 2,1 & 0,0 & 2,1 & 2,1 & 2,1 & 43,8 \\
\hline 24 & 18,0 & 576 & 17,8 & 2,2 & 2,2 & 8,9 & 2,2 & 8,9 & 6,7 & 2,2 & 2,2 & 0,0 & 4,4 & 2,2 & 2,2 & 37,8 \\
\hline 25 & 16,8 & 540 & 17,3 & 1,9 & 3,8 & 3,8 & 1,9 & 7,7 & 7,7 & 1,9 & 1,9 & 0,0 & 1,9 & 1,9 & 5,8 & 42,3 \\
\hline 26 & 16,5 & 360 & 14,3 & 2,4 & 2,4 & 9,5 & 2,4 & 7,1 & 9,5 & 2,4 & 2,4 & 0,0 & 2,4 & 2,4 & 2,4 & 40,5 \\
\hline 27 & 15,6 & 480 & 17,0 & 2,1 & 4,3 & 8,5 & 0,0 & 8,5 & 8,5 & 2,1 & 2,1 & 0,0 & 4,3 & 2,1 & 2,1 & 38,3 \\
\hline 28 & 15,2 & 504 & 15,9 & 2,3 & 4,5 & 6,8 & 2,3 & 9,1 & 6,8 & 2,3 & 2,3 & 0,0 & 4,5 & 2,3 & 2,3 & 38,6 \\
\hline 29 & 14,3 & 432 & 12,0 & 2,0 & 4,0 & 10,0 & 2,0 & 8,0 & 6,0 & 2,0 & 2,0 & 0,0 & 2,0 & 2,0 & 4,0 & 44,0 \\
\hline 30 & 13,3 & 240 & 10,3 & 2,6 & 2,6 & 7,7 & 2,6 & 7,7 & 7,7 & 0,0 & 0,0 & 0,0 & 2,6 & 2,6 & 2,6 & 51,3 \\
\hline 31 & 12,9 & 468 & 15,9 & 2,3 & 2,3 & 6,8 & 0,0 & 9,1 & 6,8 & 2,3 & 2,3 & 0,0 & 4,5 & 2,3 & 2,3 & 43,2 \\
\hline 32 & 12,0 & 456 & 18,0 & 2,0 & 2,0 & 10,0 & 2,0 & 10,0 & 6,0 & 2,0 & 2,0 & 0,0 & 2,0 & 2,0 & 4,0 & 38,0 \\
\hline 33 & 11,7 & 660 & 23,4 & 4,3 & 2,1 & 4,3 & 2,1 & 6,4 & 8,5 & 2,1 & 2,1 & 0,0 & 2,1 & 0,0 & 0,0 & 42,6 \\
\hline
\end{tabular}




\begin{tabular}{|c|c|c|c|c|c|c|c|c|c|c|c|c|c|c|c|c|}
\hline 34 & 9,1 & 660 & 26,1 & 2,2 & 4,3 & 10,9 & 2,2 & 6,5 & 8,7 & 2,2 & 2,2 & 0,0 & 2,2 & 2,2 & 0,0 & 30,4 \\
\hline 35 & 8,6 & 300 & 10,4 & 2,1 & 4,2 & 10,4 & 2,1 & 8,3 & 8,3 & 2,1 & 2,1 & 0,0 & 2,1 & 2,1 & 2,1 & 43,8 \\
\hline 36 & 8,0 & 540 & 18,8 & 0,0 & 2,1 & 10,4 & 2,1 & 6,3 & 10,4 & 2,1 & 4,2 & 0,0 & 2,1 & 2,1 & 6,3 & 33,3 \\
\hline 37 & 7,7 & 690 & 25,5 & 3,9 & 2,0 & 5,9 & 2,0 & 7,8 & 5,9 & 0,0 & 0,0 & 0,0 & 2,0 & 2,0 & 3,9 & 39,2 \\
\hline
\end{tabular}

Fonte: Dados da Pesquisa (2020).

Quando analisada a grade de cada IES, é evidenciado que nenhuma delas possui uma disciplina para tratar dos Princípios de Contabilidade e Normas Brasileiras de Contabilidade de forma segregada, como até então era apresentado o conteúdo dos editais do Exame de Suficiência. Apesar da resolução n 750/1993 que dispõe sobre os princípios de contabilidade ter sido revogada, seus valores se mostram presentes de maneira indireta nas normas contábeis. Foi identificado que as Normas Brasileiras de Contabilidade são geralmente tratadas por disciplinas associadas à Contabilidade Geral (contabilidade básica, introdutória ou societária) e Teoria da Contabilidade, uma vez que é fundamental no desenvolvimento das atividades contábeis.

Outro destaque apresentado na tabela é a quantidade de carga horária destinada a outras disciplinas que não estão no escopo do Exame de Suficiência (de 27,3 a 51,3\%), como por exemplo: Administração, Economia, Psicologia, Sociologia, Filosofia, Tecnologia da Informação, Metodologia do Trabalho Científico, Estágio Supervisionado, Trabalho de Conclusão de Curso, etc. Além disso, conta também com matérias optativas com conteúdo específico na área contábil como: Contabilidade Rural, Bancária, Internacional, da Construção Civil, etc. Especificamente em relação à Contabilidade Geral os percentuais variam de 10,3 a 26,1\% em relação à carga horária total descrita na matriz curricular de cada IES.

Para verificar a existência de relação entre as variáveis foi utilizado o Coeficiente de Correlação de Pearson (r). Para Figueiredo e Silva (2009), esse coeficiente é uma medida de associação linear entre variáveis, mensurando a direção e o grau de correlação.

Seguindo a interpretação de Mukaka (2012) para os resultados apresentados, tem-se que qualquer valor menor que $|0,3|$ será considerado desprezível para a análise. Portanto, não se pode dizer que há uma associação linear entre as variáveis estudadas nesse trabalho.

Para evidenciar esse resultado de maneira estatística, foi utilizado a regressão linear simples utilizando a Carga Horária total de Contabilidade Geral como variável independente (x) e o Índice de Aprovação no Exame de Suficiência como variável dependente (y), conforme Tabela 5. Embora mantenha-se com coeficiente negativo, a significância estatística não permite validar essa relação negativa.

Tabela 5 - Análise de Regressão Linear Simples

\begin{tabular}{|c|c|c|c|c|}
\hline Variável & Coeficientes & Erro padrão & Stat $t$ & p-valor \\
\hline Interseção & 0,366769 & 0,108258 & 3,387920266 & 0,001755 \\
\hline Carga Horária CGeral & $-0,00025$ & 0,000218 & $-1,14196621$ & 0,261221 \\
\hline
\end{tabular}

Fonte: Dados da Pesquisa (2020).

Para execução do teste de hipóteses, adota-se o p-valor para avaliar o nível de significância do coeficiente beta referente à Carga Horária total das disciplinas relacionadas a Contabilidade Geral. Dada uma hipótese nula, o p-valor reflete a probabilidade de se obter uma estatística de teste igual a zero. Na regressão 
apresentada, o p-valor 0,26 é muito superior ao nível de significância de $5 \%(0,05)$. Portanto, não é possível rejeitar que, estatisticamente, é nula a relação entre a Carga Horária total das disciplinas de Contabilidade Geral e o Índice de Aprovação no Exame de suficiência.

Também se faz necessária uma análise para verificar a influência no índice de aprovação do Exame de Suficiência em relação a IES e respectivo curso de Ciências Contábeis, assim como outra medida de avaliação do desempenho do estudante, além da carga horária de Contabilidade Geral para ratificar a aceitação da hipótese nula estipulada.

Como o objetivo principal desse trabalho é verificar a influência da Carga Horária das disciplinas relativas a Contabilidade Geral no índice de aprovação no Exame de Suficiência, ela será inicialmente testada em conjunto com os demais indicadores. A tabela 6 apresenta a análise de regressão linear múltipla que contempla o índice de aprovação no Exame de Suficiência como a variável dependente, e a Carga horária total de Contabilidade Geral, $\mathrm{Cl}$, CPC e ENADE como variáveis explicativas.

Tabela 6 - Análise dos Múltiplos Determinantes

\begin{tabular}{lcccc}
\hline \multicolumn{1}{c}{ Variável } & Coeficientes & Erro padrão & Stat t & p-valor \\
\hline Interseção & 0,0797 & 0,1684 & 0,4734 & 0,6391 \\
Carga Horária CGeral & $-0,0002$ & 0,0002 & $-1,0712$ & 0,2920 \\
Cl & 0,0213 & 0,0333 & 0,6400 & 0,5267 \\
ENADE & 0,1198 & 0,0307 & 3,9014 & 0,0005 \\
CPC & $-0,0485$ & 0,0373 & $-1,3004$ & 0,2027 \\
\hline
\end{tabular}

Fonte: Dados da Pesquisa (2020)

Baseado nesse modelo e dado um nível de significância de 5\%, pode-se afirmar que apenas o "ENADE" é estatisticamente significativo, ou seja, é considerado estatisticamente diferente de zero. Sendo assim, as demais variáveis explicativas não exercem influência na explicação de variação do índice de aprovação no Exame de Suficiência. Novamente é refutada a hipótese desse trabalho, reafirmando que a carga horária total das disciplinas de Contabilidade Geral não exerce influência significativa no desempenho dos estudantes no exame. Sendo assim, esse teste ratifica os achados na teoria subjacente acerca do valor agregado das Instituições de Ensino, corroborando o fato de que o desempenho do estudante é impactado principalmente por características próprias individuais, enquanto as Instituições de Ensino não agregam tanto ao que se refere à diferença de rendimento entre essas.

Outra possível forma de avaliar a influência dos fatores inerentes aos estudantes, seria a verificação da natureza da IES. De forma indireta é possível identificar algumas características do estudante (por exemplo: renda familiar e escola do ensino médio) baseadas na natureza da IES, conforme Ferreira (2015) ao atribuir que aluno de IES privada tende a ter desempenho menor do que alunos de IES pública (no ensino médio). Os estudantes de escolas privadas, com melhor condição socioeconômica, teriam desempenho superior ao daqueles que cursaram ensino médio em escola pública e, posteriormente, ingressam em IES particular.

As IES de natureza pública são normalmente a primeira opção dos estudantes, pelo fato delas já possuírem o estereótipo associado como sinônimo de qualidade (Santos et al, 2010). Além disso, há ainda 0 fato de possuem processos de admissão (vestibulares) que selecionam aqueles estudantes com maior rendimento. Partindo da premissa apresentada que o valor agregado da instituição de ensino no desempenho do estudante é pequeno, o desempenho dos estudantes medido pela variável do ENADE ou Exame de 
Suficiência ao final da graduação tende a ser também superior nas Universidades Públicas se comparado com outras instituições.

A fim de averiguar novamente a questão do valor agregado, mas sob a ótica da natureza da IES, foi adicionada uma variável dummy ao modelo apresentado, conforme consta na Tabela 7. Essa variável indica valor 0 para natureza institucional privada e 1 para pública.

Tabela 7 - Análise com Inclusão da Natureza da IES

\begin{tabular}{lcccc}
\hline \multicolumn{1}{c}{ Variável } & Coeficientes & Erro padrão & Stat t & p-valor \\
\hline Interseção & $-0,0454$ & 0,1145 & $-0,3965$ & 0,6943 \\
Cl & 0,0267 & 0,0272 & 0,9817 & 0,3336 \\
ENADE & 0,0321 & 0,0329 & 0,9775 & 0,3357 \\
CPC & 0,0217 & 0,0348 & 0,6231 & 0,5377 \\
Natureza IES & 0,2633 & 0,0626 & 4,2034 & 0,0002 \\
\hline
\end{tabular}

Fonte: Autoria Própria (2020)

No novo cenário apresentado, tem-se evidências que apenas a variável "Natureza Institucional" se mostra estatisticamente significativa à $5 \%$, enquanto as variáveis "Cl" e "CPC" permanecem sem significância estatística e "ENADE" passou a não ter significância nesse modelo. Essas evidências não contrapõem achados anteriores, de que a IES exerce pouca influência no desempenho do estudante, enquanto a Natureza Institucional pode ser considerada uma proxy para características intrínsecas do aluno, mensurando alguns fatores de maneira indireta.

\section{Considerações Finais}

O Exame de Suficiência, requisito para o título de Contador, se tornou um aspecto relevante na formação e valorização do profissional contabilista. A aplicação dessa prova traz melhorias no ensino superior, servindo como um parâmetro de avaliação não só dos estudantes, mas também das Instituições de Ensino.

Este trabalho teve como objetivo geral verificar a existência de relação entre carga horária total das disciplinas relacionadas à Contabilidade Geral e o índice de aprovação dos estudantes no Exame de Suficiência no estado da Bahia. Para verificação da hipótese proposta, foram utilizadas técnicas de análise de correlação linear e regressão linear simples.

Através dessas análises foi possível alcançar o objetivo da pesquisa, quantificando a incidência histórica das questões do Exame de Suficiência, identificando a carga horária total das disciplinas relacionadas à Contabilidade Geral e comparando a estrutura das grades curriculares dos cursos em relação às questões de Contabilidade Geral do Exame de Suficiência.

No decorrer da pesquisa, através da análise e discussão dos dados, foi identificado que os resultados obtidos refutam a hipótese estabelecida. Sendo assim, não é possivvel afirmar que há uma associação linear entre a carga horária total das disciplinas relacionadas à Contabilidade Geral e o Índice de Aprovação das IES avaliadas na amostra. 
Sugere-se que as características inerentes ao indivíduo exercem influência significativa no desempenho do mesmo, pois melhores resultados no ENADE se relacionam com melhores resultados no Exame de Suficiência, todavia na presença da variável institucional, natureza da IES, esta passou a explicar 0 desempenho no Exame de Suficiência.

Este trabalho apresenta como limitações as seguintes características: Amostragem não-probabilística em virtude da pequena população; Missings e imputação do valor médio para cada variável; Limitação dos dados disponíveis no site do CFC; e Classificação subjetiva das disciplinas para mensuração da carga horária.

Por fim, tendo em vista a relevância do assunto no contexto acadêmico, que impacta diretamente a formação dos profissionais contabilistas, sugere-se como pesquisa para trabalhos futuros a aplicação de metodologia semelhante à nível nacional para aumentar a amostra, controlando seus efeitos por região ou Estado em razão de possíveis efeitos culturais. Adicionalmente, sugere-se a investigação de outros possíveis fatores que impactem no índice de aprovação, principalmente no que se refere ao perfil dos estudantes, já que esse é o maior influenciador do seu desempenho.

\section{Referências}

Assunção, F. (2012). Estratégias para tratamento de variáveis com dados faltantes durante o desenvolvimento de modelos preditivos. Tese de Doutorado, Universidade de São Paulo.

Brasil. (1946) Decreto-Lei n. 9.295. Cria o Conselho Federal de Contabilidade, define as atribuições do Contador e do Guarda-livros, e dá outras providências. Recuperado em http://www.planalto.gov.br/ccivil_03/Decreto-Lei/Del9295.htm. Acesso em 10 de maio de 2020 .

Brasil. (2010). Lei n. 12.249. [...] altera os Decretos-Leis ns 9.295, de 27 de maio de 1946 [...]; e dá outras providências. Recuperado em www.planalto.gov.br/ccivil_03/_ato2007-2010/2010/lei//12249.htm>. Acesso em 10 de maio de 2020.

Bertolin, J. C., \& Marcon, T. (2015). O (des) entendimento de qualidade na educação superior brasileira-Das quimeras do provão e do ENADE à realidade do capital cultural dos estudantes. Avaliação: Revista da Avaliação da Educação Superior (Campinas), 20(1), 105-122.

Castilho, E. S. D. (2013). Qualidade do ensino de custos na UFG: uma visão em relação ao exame de suficiência. Monografia Universidade Federal de Goiás. Goiânia.

Casartelli, A.O, Bittencourt, H. R., de Morais Rodrigues, A. C., de Moraes, G. I., \& Guerra, G. L. (2014). Instituições de ensino superior comunitárias: questões atuais. REDES: Revista do Desenvolvimento Regional, 19(3), 248-269.

Cruz, M. C. (2011). A importância da regulamentação da profissão contábil: o Exame de Suficiência. Recuperado em http://www.ice.edu.br/TNX/storage/webdisco/2011/11/10/. Acesso em 7 de maio de 2018.

Coleman, J. S. (1968). Equality of educational opportunity. Integrated Education, 6(5), 19-28.

Conselho Federal de Contabilidade - CFC. (2015). Resolução 2015/001486. Regulamenta o Exame de Suficiência. Recuperado em http://cfc.org.br/wp-content/uploads/2016/01/RES_1486.doc. Acesso em 20 de outubro de 2017.

Conselho Federal de Contabilidade - CFC. (2020). Relatórios Estatísticos do Exame de Suficiência. Regulamenta o Exame de Suficiência. Recuperado em https://cfc.org.br/registro/exame-de-suficiencia/relatorios-estatisticos-do-exame-de-suficiencia/. Acesso em 03 de agosto de 2020.

Conselho Nacional de Educação - CNE. (2004). Resolução CNE/CES 10. Institui as Diretrizes Curriculares Nacionais para o Curso de Graduação em Ciências Contábeis. Recuperado em http://portal.mec.gov.br/cne/arquivos/pdf/rces10_04.pdf. Acesso em 20 de outubro de 2017.

De Negri, V. C. (2017). Exame de suficiência-identificação dos principais conteúdos abordados e as relações existentes com o índice de aprovação. Monografia - Universidade de Caxias do Sul. Caxias do Sul. 
Ferreira, M. A. (2015). Determinantes do desempenho discente no ENADE em cursos de Ciências Contábeis. Dissertação Universidade Federal de Uberlândia. Uberlândia.

Figueiredo Filho, D. B., \& Silva Júnior, J. A. D. (2009). Desvendando os Mistérios do Coeficiente de Correlação de Pearson (r). Revista Política Hoje, 18(1).

Fraga, S. S., \& Broietti, C. (2016). A Relação Entre as Questões do Exame de Suficiência, Do Enade e do Plano de Ensino de um Curso de Ciências Contábeis. In II Encontro Anual de Iniciação Científica da Unespar.

Helder, R. R. (2006). Como fazer análise documental. Porto, Universidade de Algarve.

Instituto Nacional de Estudos e Pesquisas Educacionais Anísio Teixeira - INEP. (2018). Conceito Preliminar de Curso. Recuperado em http://portal.inep.gov.br/conceito-preliminar-de-curso-cpc->. Acesso em 8 de junho de 2018.

Instituto Nacional de Estudos e Pesquisas Educacionais Anísio Teixeira - INEP. (2018). ENADE. Recuperado em http://portal.inep.gov.br/conceito-preliminar-de-curso-cpc->. Acesso em 8 de junho de 2018.

Jencks, C. (1972). Inequality: A reassessment of the effect of family and schooling in America.

Kounrouzan, M. C., Miloca, L. M., Ferraz, L. M. S., \& Ponciano, S. A. B. (2010). A importância do retorno do exame de suficiência. Encontro de Estudantes de Ciências Contábeis, II.

Madeira, G. J., Mendonça, K. F. C., \& Abreu, S. M. (2003). A disciplina teoria da contabilidade nos exames de suficiência e provão. Contabilidade Vista \& Revista, 14, 103-122.

Marion, J. C. (2001). $O$ ensino da Contabilidade. São Paulo: $2^{a}$ Edição. Editora Atlas SA.

Mukaka, M. M. (2012). A guide to appropriate use of correlation coefficient in medical research. Malawi medical journal, 24(3), 69-71.

Moraes, E. F. D. (2005). 0 impacto das grades curriculares do curso de bacharelado em Ciência Contábeis no desempenho das instituições de ensino superior do Estado da Paraíba no exame de suficiência no período de 2000 a 2004. Dissertação - UnB, UFPB, UFPE e UFRN, João Pessoa.

Pinheiro, R. M., Castro, G. C. D., Silva, H. H., \& Nunes, J. M. G. (2006). Comportamento do consumidor e pesquisa de mercado. 3a edição. Rio de Janeiro.

Quintana, A. C., Perazo, A. N. C., \& Fernandes, V. L. P. (2013). A grade curricular dos cursos de ciências contábeis e os resultados institucionais no ENADE: um estudo nas disciplinas da área da contabilidade financeira e de orçamento. Revista Gestão Universitária na América Latina-GUAL, 6(3).

Rabelo, G. (2017). Raio - X: Exame Cfc 2017.2: Plano de Emergência. Recuperado em https://dhg1h5j42swfq.cloudfront.net/2017/02/29112051/Raio-X-Exame-CFC1.pdf. Acesso em 20 de outubro de 2017.

Santos, M. J. M. D., Spers, E. E., Ponchio, M. C., \& Rocha, T. V. (2010). Heurísticas no consumo de serviços de educação superior. Revista Brasileira de Marketing, 9(1), 40-63.

Silva, A. C. R. D., Gomes, S., \& Guimarães, I. P. (2008). Educação em Contabilidade: Alguns Aspectos Crítico sugestivos do Exame Nacional de Desempenho dos Estudantes-ENADE/2006. In Congresso Brasileiro de Contabilidade (Vol. 18).

Soares, J. F., Martins, M. I., \& Assunção, C. N. B. (1998). Heterogeneidade acadêmica dos alunos admitidos na UFMG e PUC-MG. Estudos em Avaliaçao Educacional, (17), 61-72.

Soares, J. F., Ribeiro, L. M., \& Castro, C. D. M. (2001). Valor agregado de instituições de ensino superior em Minas Gerais para os cursos de Direito, Administração e Engenharia Civil. Dados, 44(2).

Triola, M. F. (1999). Introdução a estatística: livros técnicos e científicos.

Thomas, S. (1998). Value-added measures of school effectiveness in the United Kingdom. Prospects, 28(1), 91-108.

Thomas, S., \& Mortimore, P. (1996). Comparison of value-added models for secondary-school effectiveness. Research papers in education, 11(1), 5-33. 


\section{DADOS DOS AUTORES}

\section{Thiago Rios Sena}

Mestre em Contabilidade pela UFBA

Endereço: Rua Doutor Mário Campos, 47, apt 102 - Parque Bela Vista

CEP 40279-220 - Salvador / BA - Brasil

E-mail: thiagoriossena@gmail.com

Telefone: (75) 99162-0116

ORCID: https://orcid.org/0000-0003-0261-7381

\section{Jonatas Dutra Sallaberry}

Doutorando em Contabilidade pela UFSC

Endereço: CSE - Bloco G, $3^{\circ}$ andar - Sala 2 - Trindade

CEP: 88040-970 - Florianópolis / SC - Brasil

E-mail: jonatas.sallaberry@hotmail.com

Telefone: (41) 98496-6447

ORCID: https://orcid.org/0000-0001-7492-727X

\section{Contribuição dos Autores:}

\begin{tabular}{lcc}
\hline Contribuição & Thiago Sena & Jonatas Sallaberry \\
\hline 1. Concepção do assunto e tema da pesquisa & $\sqrt{ }$ & $\sqrt{ }$ \\
2. Definição do problema de pesquisa & $\sqrt{ }$ & - \\
3. Desenvolvimento das hipóteses e constructos da & $\sqrt{ }$ & \\
pesquisa (trabalhos teórico-empíricos) & & \\
4. Desenvolvimento das proposições teóricas & $\sqrt{ }$ & $\sqrt{ }$ \\
(trabalhos teóricos os ensaios teóricos) & & $\sqrt{ }$ \\
5. Desenvolvimento da plataforma teórica & $\sqrt{ }$ & - \\
6. Delineamento dos procedimentos metodológicos & $\sqrt{ }$ & - \\
7. Processo de coleta de dados & $\sqrt{ }$ & $\sqrt{ }$ \\
8. Análises estatísticas & $\sqrt{ }$ & - \\
9. Análises e interpretações dos dados coletados & $\sqrt{ }$ & $\sqrt{ }$ \\
10. Considerações finais ou conclusões da pesquisa & $\sqrt{ }$ & $\sqrt{ }$ \\
11. Revisão crítica do manuscrito & $\sqrt{ }$ & \\
12. Redação do manuscrito & $\sqrt{ }$ & \\
\hline
\end{tabular}

